УДК 676.024

\title{
ИССЛЕДОВАНИЕ СРАВНИТЕЛЬНОЙ ЭФФЕКТИВНОСТИ ПОВЫШЕНИЯ ПРОЧНОСТИ МАКУЛАТУРНОГО ФЛЮТИНГА РАЗЛИЧНЫМИ СВЯЗУющИМИ «УЛЬТРAPE3 DS»
}

\section{(C) С.Н. Кожевников}

\author{
Общество с ограниченной ответственностью «СКИФ Спешиал Кемикалз», \\ Восточная промзона, 7, Дзержинск, Нижегородская обл., 606000 (Россия), \\ e-mail: skif@skif.us
}

Рассмотрены результаты исследования влияния 9 синтезированных полиакриламидных полимерных связующих на ל-потенциал, катионную потребность массы, физико-механические показатели макулатурного флютинга - абсолютное сопротивление продавливанию, удельное сопротивление разрыву, сопротивление плоскостному сжатию, сопротивление торцевому сжатию. Синтезированы 9 образцов связующего для повышения прочности картона в сухом состоянии. Все они представляют группу продуктов с общей торговой маркой «Ультрарез DS», имеющих полиакриламидную основу, но отличающихся содержанием в своем составе некоторых специфических мономеров.

Проверку всех образцов связующего для сухого упрочнения бумаги «Ультрарез DS» осуществляли с учетом содержания активных (сухих) веществ в связующем. За норму принята смола с содержанием сухих веществ $12,5 \%$. Перед подачей смола «Ультрарез DS» разбавляется в 10 раз водой для ее более равномерного распределения в бумажной массе.

Композиция бумажной массы, в которую вводилась смола, состояла из 100 \% макулатуры марки МС-5Б, 2 сорт, в сухом состоянии, в виде обрезков гофрированного картона. Для изготовления флютинга использовали макулатурный флютинг, для лайнера - макулатурный лайнер, которые отделяли от гофрированного картона, составляющего пробу макулатуры. Макулатурная масса размалывалась в мельнице Йокро при концентрации $6 \%$ до 30 ШР, и из размолотой массы изготавливались отливки массой 125 г/м².

Непосредственно перед введением связующего в бумажную массу подается раствор полиоксихлорида алюминия (ПОХА) с расходом 0,5 кг/т (по сухому полиоксихлориду алюминия). После смешения с раствором ПОХА в бумажную массу добавляется предварительно разбавленное связующее «Ультрарез DS». Вначале производили образец флютинга без химикатов (холостая проба 1), затем отливали образец флютинга с ПОХА, расходом 0,5 кг/т (холостая проба 2), а после этого изготавливали образцы флютинга с различными расходами связующего - 2, 4, 6, 8 кг/т.

Контролируемыми показателями бумажной массы был электрокинетический потенциал (ל-потенциал) и катионная потребность, а флютинга - физико-механические свойства. Механические испытания проведены по стандартным методикам после кондиционирования образцов при температуре $23 \pm 1{ }^{\circ} \mathrm{C}$ и относительной влажности воздуха $50 \pm \%$. Установлено, что все связующие оказывают влияние на свойства массы и качество картона, но наиболее сильный эффект снижения ל-потенциала и практически до нулевого уровня уменьшение катионной потребности имеет место при добавках связующих 3,4 и 5. Эти же связующие способны с наибольшим эффектом повышать механические свойства флютинга.

Ключевые слова: полиакриламидное связующее, макулатура, флютинг.

\section{Введение}

Значение химических вспомогательных веществ (ХBB), часто называемых функциональными химическими веществами (ФХВ), в технологии бумаги, картона и изделий из них велико и постоянно возрастает. К их числу принадлежат химические средства для повышения механической прочности. Одни, как, например, продукты на основе крахмала различного происхождения (картофельный, кукурузный, топиоковый и др.), на основе целлюлозы - натрийкарбоксиметилцеллюлоза, широко применяются. Другие, относящиеся к синтетическим, значительно уступают первым в востребованности и, естественно, в объемах потребления [1-5]. Однако, учитывая возможности современного химического синтеза, получаемым продуктам можно

Кожевников Сергей Юрьевич - руководитель научнотехнических программа развития отдела инновационного развития, кандидат технических наук, e-mail: skif@skif.us придавать целевой комплекс свойств, превосходящий возможности природного синтеза [5]. 
В выполненной работе ставилась цель проведения сравнительных исследований свойств серии синтезированных полимерных связующих для установления их упрочняющей способности при добавках в макулатурную массу при производстве бумаги для гофрирования (флютинг).

\section{Проведение исследований и обсуждение результатов}

Для исследований в ООО «СКИФ Спешиал Кемикалз» были синтезированы 9 образцов связующего для повышения прочности картона в сухом состоянии. Все они представляют собой группу продуктов с общей торговой маркой «Ультрарез DS», имеющих полиакриламидную основу, но отличающихся содержанием в составе некоторых специфических мономеров. Характеристика образцов представлена в таблице 1. Композиция бумажной массы, в которую вводилась смола, состояла из 100\% макулатуры марки МС-5Б, 2 сорт, в сухом состоянии в виде обрезков гофрированного картона. Для изготовления флютинга использовали макулатурный флютинг, для лайнера - макулатурный лайнер, которые отделяли от гофрированного картона, составляющего пробу макулатуры. Макулатурная масса размалывалась в мельнице Йокро при концентрации 6\% до 30 ШР, и из размолотой массы изготавливались отливки массой 125 г/м².

Проверку образцов связующего для сухого упрочнения бумаги «Ультрарез DS» осуществляли с учетом содержания активных (сухих) веществ в связующем. За норму принята смола с содержанием сухих веществ 12,5\%. Например, при расходе смолы «Ультрарез DS» с концентрацией 12,5\% - 4 кг/т, расход смолы «Ультрарез DS» с концентрацией 10\% принят 5 кг/т, а расход смолы «Ультрарез DS» с концентрацией $15 \%$ - 3,3 кг/т. Перед подачей смола «Ультрарез DS» разбавляется в 10 раз водой для более равномерного распределения смолы в бумажной массе.

Непосредственно перед добавлением связующего в бумажную массу подается раствор полиоксихлорида алюминия (ПОХА) с расходом 0,5 кг/т (по сухому полиоксихлориду алюминия). После смешения с раствором ПОХА в бумажную массу подается предварительно разбавленное связующее «Ультрарез DS». Вначале производили образец флютинга без химикатов (холостая проба 1), затем отливали образец флютинга с ПОХА, расходом 0,5 кг/т (холостая проба 2), после этого изготавливали образцы флютинга с различными расходами связующего - 2, 4, 6, 8 кг/т.

Контролируемыми показателями бумажной массы были: электрокинетический потенциал ( $\zeta$-потенциал) и катионная потребность, а флютинга - физико-механические свойства. Механические испытания проведены по стандартным методикам после кондиционирования образцов при температуре $23 \pm 1^{\circ} \mathrm{C}$ и относительной влажности воздуха $50 \%$.

Экспериментальные данные о влиянии связующих на 丂-потенциал и катионную потребность представлены в таблице 2.

Результаты экспериментов, приведенные в таблице 2, показывают следующее:

a) все вводимые в массу связующие приводят к снижению ее ร-потенциала, хотя и в разной степени, а также катионной потребности (кроме образца 6 - DS-150, цеховой стандартный), введение которого не приводит к снижению катионной потребности;

б) сильный эффект снижения отрицательного Ђ-потенциала дает введение связующих 1-5; меньшее снижение дают образцы 6, 7 и 9; наибольший эффект дают связующие 1, 3 и 5, которые перезаряжают мас-

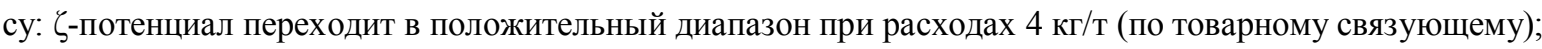

в) резкое снижение катионной потребности обеспечивают связующие 2, 4; практически до 0 снижают катионную потребность связующие 3, 4 и 5.

Таблица 1. Характеристика исследованных продуктов «Ультрарез DS»

\begin{tabular}{|c|c|c|c|c|}
\hline \multirow{2}{*}{$\begin{array}{c}\text { № } \\
\text { образца }\end{array}$} & \multirow{2}{*}{ "Образец } & \multicolumn{3}{|c|}{ Характеристики образца } \\
\hline & & сухой остаток T.S., \% & $\mathrm{pH}$ & вязкость при $25^{\circ} \mathrm{C}$, сПз \\
\hline 1 & DS-Q, цеховая варка $12,5 \%$ на мономере X & 12,44 & 4,04 & 2300 \\
\hline 2 & DS, $12,5 \%$ на мономере Y & 12,48 & 3,90 & 1100 \\
\hline 3 & DS, $12,5 \%$ на мономере $\mathrm{Y}_{1}$ & 12,72 & 3,31 & 1180 \\
\hline 4 & DS, $10,5 \%$ на мономере $Z$ & 10,42 & 3,20 & 1600 \\
\hline 5 & DS-Q, цеховая варка $10,5 \%$ на мономере X & 10,63 & 3,87 & 1960 \\
\hline 6 & DS-150, цеховой стандартный & 15,3 & 4,47 & 2640 \\
\hline 7 & DS-30, цеховой стандартный & 30,77 & 4,55 & 1640 \\
\hline 8 & DS, сополимер крахмала с акрилатами & 15,72 & 4,47 & 700 \\
\hline 9 & DS, на мономере W & 12,79 & - & 6800 \\
\hline
\end{tabular}

ППолный химический состав образцов не раскрывается, так как проводится патентование 
Таблица 2. Результаты определения электрокинетических характеристик бумажной массы с добавками синтезированных связующих

\begin{tabular}{|c|c|c|}
\hline Расход смолы, кг/т & Дзета потенциал, $\mathrm{mV}$ & Катионная потребность, мл \\
\hline Без химикатов & $-16,65$ & 0,127 \\
\hline С добавками ПОХА & $-14,10$ & 0,222 \\
\hline \multicolumn{3}{|c|}{1 - DS-Q, цеховая варка 12,5\% на мономере X } \\
\hline 2 & $-7,30$ & 0,157 \\
\hline 4 & $-3,50$ & 0,109 \\
\hline 6 & $-0,20$ & 0,078 \\
\hline 8 & 2,00 & 0,053 \\
\hline \multicolumn{3}{|c|}{2 - DS, $12,5 \%$ на мономере $\mathrm{Y}$} \\
\hline 2 & $-8,30$ & 0,150 \\
\hline 4 & $-5,90$ & 0,139 \\
\hline 6 & $-3,10$ & 0,107 \\
\hline 8 & $-1,80$ & 0,075 \\
\hline \multicolumn{3}{|c|}{3 - DS, $12,5 \%$ на мономере $\mathrm{Y}_{1}$} \\
\hline 2 & $-8,65$ & 0,144 \\
\hline 4 & $-4,00$ & 0,125 \\
\hline 6 & $-0,60$ & 0,082 \\
\hline 8 & 4,90 & 0,001 \\
\hline \multicolumn{3}{|c|}{4 - DS, $10,5 \%$ на мономере $Z$} \\
\hline 2,4 & $-8,45$ & 0,113 \\
\hline 4,8 & $-5,40$ & 0,102 \\
\hline 7,2 & $-2,60$ & 0,085 \\
\hline 9,5 & $-0,20$ & 0,018 \\
\hline \multicolumn{3}{|c|}{5 - DS-Q, цеховая варка 10,5\% X } \\
\hline 2,4 & $-6,10$ & 0,162 \\
\hline 4,8 & $-0,25$ & 0,104 \\
\hline 7,2 & 3,10 & 0,053 \\
\hline 9,5 & 5,15 & 0,004 \\
\hline \multicolumn{3}{|c|}{6 - DS-150, цеховой стандартный } \\
\hline 1,6 & $-11,55$ & 0,200 \\
\hline 3,3 & $-10,75$ & 0,228 \\
\hline 4,9 & $-10,00$ & 0,223 \\
\hline 6,5 & $-9,65$ & 0,241 \\
\hline \multicolumn{3}{|c|}{7 - DS-30, цеховой стандартный } \\
\hline 0,8 & $-12,90$ & 0,148 \\
\hline 1,6 & $-11,10$ & 0,148 \\
\hline 2,4 & $-9,90$ & 0,142 \\
\hline 3,3 & $-9,30$ & 0,136 \\
\hline \multicolumn{3}{|c|}{8 - DS, сополимер крахмала с акрилатами } \\
\hline 1,6 & $-10,25$ & 0,193 \\
\hline 3,2 & $-7,15$ & 0,156 \\
\hline 4,8 & $-4,40$ & 0,114 \\
\hline 6,4 & $-2,35$ & 0,105 \\
\hline \multicolumn{3}{|c|}{9 - DS , на мономере W } \\
\hline 1,95 & $-15,10$ & 0,202 \\
\hline 3,91 & $-10,60$ & 0,171 \\
\hline 5,86 & $-11,65$ & 0,174 \\
\hline 7,82 & $-8,25$ & 0,123 \\
\hline
\end{tabular}

В образцах изготовленной бумаги с добавками связующего «Ультрарез DS» определяли: абсолютное сопротивление продавливанию, удельное сопротивление разрыву, сопротивление плоскостному сжатию, сопротивление торцевому сжатию. Результаты представлены в таблице 3.

При изготовлении образцов бумаги с первым и пятым связующим отмечены значительные смоляные затруднения, особенно при расходе смолы 6,8 кг/т, образец после отлива плохо отделялся от сетки, сетка засмаливалась. С образцами связующего 2,4,6,9 смоляные затруднения возникали при расходах более 4 кг/т.

Практически не возникало смоляных затруднений при использовании связующих 3, 7, 8. 
Таблица 3. Результаты испытаний упрочнения флютинга образцами связующего

\begin{tabular}{|c|c|c|c|c|c|c|c|c|c|c|}
\hline \multirow{2}{*}{$\begin{array}{c}\text { Расход } \\
\text { связую- } \\
\text { щего, } \\
\text { кг/т }\end{array}$} & \multicolumn{2}{|c|}{$\begin{array}{l}\text { Сопротивление } \\
\text { продавливанию }\end{array}$} & \multicolumn{2}{|c|}{ Разрывная длина } & \multicolumn{2}{|c|}{$\begin{array}{l}\text { Удельное сопро- } \\
\text { тивление разрыву }\end{array}$} & \multicolumn{2}{|c|}{$\begin{array}{c}\text { Сопротивление } \\
\text { плоскостному } \\
\text { сжатию } \\
\end{array}$} & \multicolumn{2}{|c|}{$\begin{array}{c}\text { Сопротивление } \\
\text { торцевому сжа- } \\
\text { тию, кН/м }\end{array}$} \\
\hline & кПа & $\%$ & M & $\%$ & кH/м & $\%$ & $\mathrm{H}$ & $\%$ & & \\
\hline $\begin{array}{c}\text { Без } \\
\text { добавок }\end{array}$ & 334 & 100 & 4150 & 100 & 4,93 & 100 & 208 & 100 & 1,66 & 100 \\
\hline C ПОХА & 351 & 105,1 & 4150 & 100,0 & 4,93 & 100,0 & 216 & 103,8 & 1,74 & 104,8 \\
\hline \multicolumn{11}{|c|}{1 - DS-Q, цеховая варка 12,5\% на мономере X } \\
\hline 2 & 392 & 117,4 & 4500 & 108,4 & 5,83 & 118,3 & 233 & 112,0 & 2,00 & 120,5 \\
\hline 4 & 351 & 105,1 & 3800 & 91,6 & 4,25 & 86,2 & 239 & 114,9 & 1,76 & 106,0 \\
\hline 6 & 403 & 120,7 & 4150 & 100,0 & 5,12 & 103,9 & 267 & 128,4 & 2,33 & 140,4 \\
\hline 8 & 422 & 126,3 & 3300 & 79,5 & 3,89 & 78,9 & 253 & 121,6 & 2,26 & 136,1 \\
\hline \multicolumn{11}{|c|}{2 - DS, 12,5\% на мономере Y } \\
\hline 2 & 416 & 124,6 & 4000 & 96,4 & 5,03 & 102,0 & 240 & 115,4 & 2,10 & 126,5 \\
\hline 4 & 377 & 112,9 & 4300 & 103,6 & 5,41 & 109,7 & 269 & 129,3 & 2,41 & 145,2 \\
\hline 6 & 406 & 121,6 & 3850 & 92,8 & 4,74 & 96,1 & 256 & 123,1 & 2,40 & 144,6 \\
\hline 8 & 447 & 133,8 & 4550 & 109,6 & 5,61 & 113,8 & 258 & 124,0 & 2,41 & 145,2 \\
\hline \multicolumn{11}{|c|}{3 - DS, $12,5 \%$ на мономере $\mathrm{Y}_{1}$} \\
\hline 2 & 380 & 113,8 & 4050 & 97,6 & 5,14 & 104,3 & 268 & 128,8 & 2,19 & 131,9 \\
\hline 4 & 419 & 125,4 & 3700 & 89,2 & 4,54 & 92,1 & 250 & 120,2 & 2,29 & 138,0 \\
\hline 6 & 359 & 107,5 & 3600 & 86,7 & 4,53 & 91,9 & 267 & 128,4 & 2,21 & 133,1 \\
\hline 8 & 508 & 152,1 & 4350 & 104,8 & 5,77 & 117,0 & 268 & 128,8 & 2,68 & 161,4 \\
\hline \multicolumn{11}{|c|}{4 - DS $10,5 \%$ на мономере Z } \\
\hline 2,4 & 536 & 160,5 & 3150 & 75,9 & 4,37 & 88,6 & 217 & 104,3 & 2,05 & 123,5 \\
\hline 4,8 & 489 & 146,4 & 4000 & 96,4 & 4,92 & 99,8 & 207 & 99,5 & 2,04 & 122,9 \\
\hline 7,2 & 494 & 147,9 & 4700 & 113,3 & 5,85 & 118,7 & 237 & 113,9 & 2,29 & 138,0 \\
\hline 9,5 & 484 & 144,9 & 4700 & 113,3 & 5,92 & 120,1 & 249 & 119,7 & 2,46 & 148,2 \\
\hline \multicolumn{11}{|c|}{5 - DS-Q, цеховая варка $10,5 \%$ на мономере X } \\
\hline 2,4 & 487 & 145,8 & 3500 & 84,3 & 4,59 & 93,1 & 236 & 113,5 & 2,05 & 123,5 \\
\hline 4,8 & 511 & 153,0 & 4300 & 103,6 & 5,31 & 107,7 & 249 & 119,7 & 2,37 & 142,8 \\
\hline 7,2 & 515 & 154,2 & 3350 & 80,7 & 4,61 & 93,5 & 265 & 127,4 & 2,23 & 134,3 \\
\hline 9,5 & 458 & 137,1 & 4950 & 119,3 & 6,28 & 127,4 & 238 & 114,4 & 2,32 & 139,8 \\
\hline \multicolumn{11}{|c|}{6 - DS-150, цеховой стандартный } \\
\hline 1,6 & 531 & 159,0 & 2850 & 68,7 & 3,75 & 76,1 & 229 & 110,1 & 2,33 & 140,4 \\
\hline 3,3 & 514 & 153,9 & 3150 & 75,9 & 4,22 & 85,6 & 237 & 113,9 & 2,34 & 141,0 \\
\hline 4,9 & 501 & 150,0 & 4250 & 102,4 & 5,77 & 117,0 & 251 & 120,7 & 2,17 & 130,7 \\
\hline 6,5 & 476 & 142,5 & 4800 & 115,7 & 6,02 & 122,1 & 250 & 120,2 & 2,42 & 145,8 \\
\hline \multicolumn{11}{|c|}{7 - DS-30, цеховой стандартный } \\
\hline 0,8 & 384 & 115,0 & 4350 & 104,8 & 5,38 & 109,1 & 220 & 105,8 & 1,99 & 119,9 \\
\hline 1,6 & 433 & 129,6 & 4550 & 109,6 & 5,68 & 115,2 & 242 & 116,3 & 2,00 & 120,5 \\
\hline 2,4 & 446 & 133,5 & 4550 & 109,6 & 5,72 & 116,0 & 230 & 110,6 & 2,02 & 121,7 \\
\hline 3,3 & 401 & 120,1 & 4200 & 101,2 & 5,29 & 107,3 & 221 & 106,3 & 2,00 & 120,5 \\
\hline \multicolumn{11}{|c|}{8 - DS, сополимер крахмала с акрилатами } \\
\hline 1,6 & 427 & 127,8 & 4550 & 109,6 & 5,74 & 116,4 & 222 & 106,7 & 2,04 & 122,9 \\
\hline 3,2 & 444 & 132,9 & 4350 & 104,8 & 5,34 & 108,3 & 238 & 114,4 & 2,22 & 133,7 \\
\hline 4,8 & 482 & 144,3 & 4650 & 112,0 & 5,74 & 116,4 & 261 & 125,5 & 2,25 & 135,5 \\
\hline 6,4 & 472 & 141,3 & 4650 & 112,0 & 5,80 & 117,6 & 258 & 124,0 & 2,05 & 123,5 \\
\hline \multicolumn{11}{|c|}{9 - DS, на мономере W } \\
\hline 1,95 & 449 & 134,4 & 4800 & 115,7 & 6,30 & 127,8 & 198 & 95,2 & 2,25 & 135,5 \\
\hline 3,91 & 491 & 147,0 & 5000 & 120,5 & 6,54 & 132,7 & 151 & 72,6 & 2,34 & 141,0 \\
\hline 5,86 & 495 & 148,2 & 5000 & 120,5 & 6,63 & 134,5 & 141 & 67,8 & 2,45 & 147,6 \\
\hline 7,82 & 468 & 140,1 & 5000 & 120,5 & 6,76 & 137,1 & 160 & 76,9 & 2,41 & 145,2 \\
\hline
\end{tabular}

Анализ данных таблицы 3 свидетельствует о том, что положительный эффект от использования связующих имеется, хотя и не во всех случаях. В каждой из серий отмечены «провалы» механики, что характерно для расходов 4-6 кг/т.

Использование 1, 2 и 3-го связующих показало похожее увеличение механической прочности - увеличилось сопротивление продавливанию и сопротивление сжатию, причем с увеличением дозировки эф- 
фект усиливается. При этом прочность при растяжении (разрывная длина практически не увеличивается, а в ряде случаев - снижается). В наибольшей степени повышается сопротивление торцевому сжатию (ССТ), которое составляет 20-60\%, особенно со связующим 3.

Образцы связующего 4, 6 уже в малых количествах (2 кг/т) приводит к резкому росту сопротивления продавливанию флютинга - на 45-55\%, а при увеличении дозировки эффект несколько снижается.

Значительное увеличение разрывной длины наблюдается для связующих 7 и 8 - до 10\%, особенно для связующего 9 - до $20 \%$.

Учитывая экспериментальные результаты, можно руководствоваться следующими положениями:

- для увеличения сопротивления продавливания больше подходят связующие 4-6;

- увеличения разрывной длины лучше использовать связующие 7-9, при этом хороший эффект наблюдается уже при малых дозировках;

- увеличения сопротивления плоскостному сжатию наиболее эффективно связующее 3;

- увеличения всех механических показателей лучшее связующее - 3, при наилучшей «технологичности» применения, под которой понимается отсутствие отрицательных явлений - «смоляных затруднений» и «провалов» механики для отдельных точек; несколько уступают связующему 3 связующие 7 и 8 , но, в целом, также показывают хороший упрочняющий эффект, без видимых технологических затруднений; также хорошая технологичность и высокий упрочняющий эффект наблюдаются у образцов 7 и 8.

Если обратиться к таблице 2, то можно видеть, что добавка связующего 3 к бумажной массе интенсивно снижает ל-потенциал массы, вплоть до перезарядки на положительный потенциал, а также интенсивно снижает, практически до нуля, катионную потребность. Это свидетельствует о высоком удержании связующего и мелкого волокна в образцах картона, создаваемом благоприятном уровне потенциального электростатического барьера в момент формирования межволоконных связей, которые обеспечивают максимальный эффект повышения прочности бумаги.

\section{Выводы}

1. Проведены исследования эффективности влияния 9 различных синтезированных полиакриламидных полимерных связующих на свойства макулатурной бумажной массы и механическую прочность макулатурного флютинга.

2. Установлено, что все связующие оказывают влияние на свойства массы и качество картона, но наиболее сильный эффект снижения Һ-потенциала и практически до нулевого уровня уменьшение катионной потребности имеет место при добавках связующих 3,4 и 5.

3. Наиболее эффективными и технологически приемлемыми связующими для повышения механической прочности флютинга являются связующие 3,7 и 8.

4. Связующее 3 и близкие к нему по эффективности 4, 5, 7 и 8 рекомендуются для широкого использования в производстве макулатурных видов бумаги и картона.

\section{Список литературь}

1. Иванов С.И. Технология бумаги. М., 2006. 696 с.

2. Кожевников С.Ю., Андреева С.Л. Упрочнение бумаги синтетической катионно-анионной полиакриламидной смолой // Химия растительного сырья. 2011. №2. С. 177-182.

3. Шабиев Р.О., Смолин А.С., Ковернинский И.Н., Кожевников С.Ю. Химия бумаги: исследование действия упрочняющих и обезвоживающих добавок // Химия растительного сырья. 2014. №4. С. 263-270.

4. Кожевников С.Ю., Вдовина О.С., Ковернинский И.Н. Химические продукты и инновации «СКИФ Спешиал Кемикалз» для бумаги и картона // Целлюлоза. Бумага. Картон. 2015. №5. С. 64-66.

5. Карманова Т.Е., Казаков Я.В., Попова А.В., Вдовина О.С., Кожевников С.Ю. Управление электрокинетическими характеристиками макулатурной бумажной массы при производстве флютинга // Использование и разработка инновационных экологически безопасных технологий переработки макулатуры при производстве всего спектра бумажно-картонной продукции : материалы 15-й Междунар. научн.-техн. конф. Караваево, 2014. С. 50-58.

6. Кожевников С.Ю., Ковернинский И.Н. Химия и технология СКИФ для бумаги. Иматра (Финляндия), 2010.91 с.

Поступило в редакиџю 20 января 2016 г.

После переработки 25 февраля 2016 г. 
Kozhevnikov S.Yu. STUDY OF COMPARATIVE EFFECTIVENESS OF INCREASING STRENGTH RECYCLED FLUTING VARIOUS BINDERS «Ultrarez DS»

Limited Liability Company "SKIF Special Chemicals", Vostochnaja promzona, 7, Dzerzhinsk, Nizhny Novgorod region, 606000 (Russia),e-mail: skif@skif.us

The study of influence of 9 synthesized polyacrylamide polymer binders to the $\zeta$-potential cationic demand mass, physical and mechanical properties of waste paper fluting - the absolute bursting strength, resistivity tear resistance plane compression, the compression resistance of the end considered in the work. 9 samples synthesized binder to improve strength paperboard in the dry state. All of them are a group of products with total sales "Ultrarez DS» mark with polyacrylamide based, but differ in the composition of the content of some specific monomers.

Check all the samples to dry binder hardening "Ultrarez DS» Paper take into account the content of active (dry) materials in the binder. The resin solids content of $12.5 \%$ is taken as normal. Resin "Ultrarez DS» diluted 10 times with water before being fed to a more uniform distribution of the resin in the paper pulp.

The composition of the pulp, which was introduced into the resin, composed of $100 \%$ recycled paper grade MS-5B, 2nd grade, in the dry state, in the form of scraps of corrugated cardboard. Recycled fluting used for the manufacture of fluting, junk ship - for the liner, which was separated from corrugated cardboard, waste paper constitutes a sample. Deinking Yokro milled in a mill at a concentration of $6 \%$ to 30 SHR and milled mass produced from castings weighing $125 \mathrm{~g} / \mathrm{m} 2$.

A solution of aluminum polyoxychloride (Pohang) at a rate of $0.5 \mathrm{~kg} / \mathrm{t}$ (dry Polioksihlorid aluminum) is applied to the pulp directly before applying the binder. Binder "Ultrarez DS», pre-diluted, is fed into the paper pulp after mixing with a solution of Pohang. First, a sample of fluting made without the addition of chemicals (blank sample 1), then the sample fluting cast with the addition of Pohang, a rate of $0.5 \mathrm{~kg} / \mathrm{t}$ (blank sample 2), and then fluting samples produced with different adhesive costs $-2,4,6.8 \mathrm{~kg} / \mathrm{t}$.

Monitored indicators of pulp were zeta potential $(\zeta$-potential) and cationic demand and fluting - physical and mechanical properties. The mechanical tests carried out according to standard procedures, after conditioning the samples at $23 \pm 1{ }^{\circ} \mathrm{C}$ and a relative humidity $50 \%$. It was found that all the binders have an effect on the properties of mass and quality of cardboard, but the strongest effect of reducing the z-potential and almost to zero decrease in cationic demand occurs when additives binders 3, 4 and 5. These binders are able to most effectively improve the mechanical properties of fluting.

Keywords: polyacrylamide binder recycled paper, fluting.

\section{References}

1. Ivanov S.I. Tekhnologiia bumagi. [Paper technology]. Moscow, 2006, 696 p. (in Russ.).

2. Kozhevnikov S.Iu., Andreeva S.L. Khimiia rastitel'nogo syr'ia, 2011, no. 2, pp. 177-182. (in Russ.).

3. Shabiev R.O., Smolin A.S., Koverninskii I.N., Kozhevnikov S.Iu. Khimiia rastitel'nogo syr'ia, 2014, no. 4, pp. $263-270$. (in Russ.).

4. Kozhevnikov S.Iu., Vdovina O.S., Koverninskii I.N. Tselliuloza. Bumaga. Karton, 2015, no. 5, pp. 64-66. (in Russ.).

5. Karmanova T.E., Kazakov Ia.V., Popova A.V., Vdovina O.S., Kozhevnikov S.Iu. Ispol'zovanie i razrabotka innovatsionnykh ekologicheski bezopasnykh tekhnologii pererabotki makulatury pri proizvodstve vsego spektra bumazhno-kartonnoi produktsii: mater. 15-i mezhdunar. nauchn.-tekhn. konf. [The use and development of innovative environmentally friendly technologies for processing waste paper in the production of the entire spectrum of paper and cardboard products: materials 15th International Scientific and Technical Conference]. Karavaevo, 2014, pp. 50-58. (in Russ.).

6. Kozhevnikov S.Iu., Koverninskii I.N. Khimiia i tekhnologiia SKIF dlia bumagi. [SKIF Chemistry and technology paper]. Imatra, Finland, 2010. 91 p. (in Russ.).

Received January 20, 2016

Revised February 25, 2016 